\title{
Brechas de la educación y su pertinencia en el tiempo
}

\section{Gaps in education and its relevance over time}

Juan Fernando Iñiguez Izquierdo

Universidad Internacional del Ecuador, Ecuador

Autor para correspondencia: jiniguez@uide.edu.ec

Fecha de recepción: 20 de julio de 2018 - Fecha de aceptación: 30 de agosto de 2018

Resumen: El presente artículo analiza la pertinencia del sistema educativo; la conceptualiza y la explica como requerimiento indispensable para la educación de calidad. El artículo explora la educación y su evolución en el tiempo, su interacción con la sociedad de la época, su evolución en el tiempo, su intención con la sociedad de la época, su impacto, las intenciones sociales referentes a la educación, quién la fundo y qué rol jugó, su nacimiento y sus características. Desde la universidad y escuela del medioevo pasando por el gran apogeo educativo de la escuela moderna, a través de un análisis de la desacralización y la proyección de la educación de hoy y sus necesidades. Es necesario examinar la pertinencia de la educación en el trascurso del tiempo para reformar las concepciones con las que se establecen parámetros de la educación moderna. Es importante, proyectar una educación con nuevas perspectivas que cumpla la tan ansiada pertinencia con la sociedad, con la industria, con la política y la cultura, que integre los problemas para ser fuente de soluciones. Se requiere una educación generadora de nuevas formas de aprendizaje y de conocimientos, que sea incluyente, universal e intercultural.

Palabras claves: pertinencia; sistema educativo; sacralización; desacralización; educación medieval; y educación moderna

Abstract: This article analyzes the relevance of the education system, starting with conceptualizing and understanding it as an indispensable requirement for quality education, necessary to rethink education. The article explores education and its evolution over time, its interaction with the society of the time and its impact, social intentions concerning education, who the background and role that juice, its birth and its characteristics. From the university and school of the Middle Ages through the great educational heyday of the modern school, through an analysis of the de-centralization and projection of today's education and its needs. It is necessary to examine the time to transform today's education, to project an education of the future with new perspectives that fulfills the much-desired relevance to society, industry, politics and culture, integrating problems to be source of solutions, an education with greater presence and influence that from the university generates new forms of learning and knowledge for basic education systems and is projected universal, intercultural and inclusive.

Key Words: pertinence; educational system; sacralization; desacralization; medieval education; and modern education 


\section{Introducción}

\section{Consideraciones generales}

\section{¿Cómo se entiende a la pertinencia?}

En asuntos; sin embargo, el concepto se discute desde perspectivas más amplias que trascienden a los requerimientos sociales, tecnológicos, políticos, e incluso intrínsecos a las instituciones de educación partiendo desde sus necesidades de vinculación social. De esta manera, la pertinencia de educación contemporánea, la pertinencia es un elemento importante de debate. Es la directriz hacia la cual apuntan los sistemas de educación, sobre todo, el sistema de educación superior siendo este el último escalón del estudiante hacia el ejercicio profesional. Pero, ¿qué implica la pertinencia y desde qué puntos debe ser abordada?

Cuando se trata el tema de la pertinencia de la educación superior se tiende a asociarla a las demandas económicas y laborales del sector productivoeducativa se la puede conceptualizar como los requerimientos sociales, científicos, económicos, políticos, culturales, e institucionales que debe cumplir la educación dentro de la coyuntura social. Carlos Tunnermann en su publicación: Pertinencia social y principios básicos para orientar el diseño de políticas de educación superior', al conceptualizar la pertinencia textualmente menciona: "El concepto de pertinencia comprende así el papel que la educación superior desempeña en la sociedad y lo que ésta espera de aquélla." (Tunnerman, 2000).

Entendiendo que la pertinencia depende del compromiso social que asuman las instituciones de educación, se torna indispensable la evolución de los planteamientos y objetivos de la educación hacia las necesidades sociales, locales, regionales y mundiales, reconvertir sus objetivos y replantearse constantemente si éstos realmente satisfacen las necesidades establecidas por su contexto. Esto supone un compromiso constante hacia la aproximación con las necesidades sociales y sobre todo exige la flexibilidad de las instituciones para responder a una sociedad dinámica en constante transformación. Refiriéndose estrictamente a la educación superior, Tunnerman analiza lo mencionado en La Conferencia Regional sobre Educación Superior (CRES-2008), donde se dejó claramente establecido que la obligación tanto del sector público como del privado es ofrecer una educación superior con calidad y pertinencia. Además, afirma que "la calidad es un concepto inseparable de la equidad y la pertinencia". A su vez, la reciente Segunda Conferencia Mundial (París, julio de 2009), en su Comunicado Final proclamó que: "Se deben perseguir al mismo tiempo metas de equidad, pertinencia y calidad". (Tunnerman, 2000)

Recalcando que la calidad y la pertinencia tienen directa relación, de hecho, la calidad de la educación debe ser evaluada en función de la pertinencia de las instituciones educativas. Este consenso de la UNESCO referido a la educación superior señala, la universidad es un reflejo para la educación en general incluyendo a la educación escolar y educación media, exige un grado de vinculación entre los diferentes niveles educativos donde la educación superior debe desarrollar conocimientos para la aplicabilidad en los otros niveles en pos de mejora de la

\footnotetext{
${ }^{1}$ Pertinencia social y principios básicos para orientar el diseño de políticas de educación superior el auto examina las conceptualizaciones de la pertinencia de la educación superior, desde las diferentes perspectivas en foros y conferencias regionales y mundiales
} 
educación, en vista de la actual percepción social de la educación que exige una reinvención de estos niveles educativos y de la formación de la niñez y la juventud en tiempos actuales de desacralización. (UNESCO, 1998).

Impera la necesidad de construcción de nuevos relatos legitimadores de la educación, en una sociedad del conocimiento que es incluyente en todos los niveles educativos donde niños y jóvenes la integran haciendo que la formación y construcción del individuo a desarrollarse en este tipo de sociedad no sea exclusiva de la universidad. (Gibbons, 1998). De lo dicho se entiende que el deber ser también es un deber de la escuela en tiempos actuales, la necesidad de refundar la educación y darle ese carácter pertinente en pos de la eficiencia y calidad que demanda la sociedad en la formación incluso escolar.

Esta necesidad es identificada por Jorge Eduardo Noro en su libro: De la escuela del pasado a la escuela del futuro, refiriéndose a las instituciones educativas de nivel escolar menciona: "La Institución escolar de nuestros días debe satisfacer por igual dos exigencias de la sociedad: (1) por una parte los planteos organizacionales que le demandan eficiencia y calidad, (2) por otra las expectativas de los usuarios que le reclaman acompañamiento, educación y niveles crecientes de humanidad. Propone integrar los esfuerzos y las acciones para mantener a la escuela como un organismo vivo y al mismo tiempo compartir estrategias para dotarla de recursos creativos definiendo una efectiva respuesta a la comunidad. Se trata de un nuevo lenguaje institucional que dialoga con las riquezas del pasado (identidad) y con las imposiciones del presente (transformaciones)" (Noro J. E., 2015). Este planteamiento exige una transformación que provenga del estudio de las necesidades de una sociedad globalizada, entendiéndose globalizada no como una situación amenazadora de la cultura sino como instrumento para conocer la identidad cultural de cada pueblo y respetar la diversidad de cada individuo, de igual manera exige para la escuela un nuevo replanteamiento filosófico, una nueva concepción de la realidad, una nueva visión de la persona y su relación con el trabajo y la producción.

Forzados por la necesidad de re plantear la escuela dentro de la nueva sociedad del conocimiento y reinventar la nueva educación inclusiva, globalizadora, humanista y respetuosa con la diversidad, bautizada con los valores propios que requiere la época actual y que corresponda a los vigentes requerimientos de refundación educativa, debemos proponer en una educación que refleje ser pertinente con estos planteamientos sociales y globales. Tres ejes interactúan en la percepción de la pertinencia, uno de ellos en la actualidad es la percepción de los sectores productivos frente al conocimiento; es decir, insertar conocimiento a la organización. El segundo es el del Estado, el tercero se refiere a los cambios en los modos de producción del conocimiento.

\section{¿Qué rol juega?}

La pertenecía se debe examinar en los diferentes niveles educativos, tal como se afirma en el documento de la UNESCO titulado: La educación del siglo XXI y citado por Tunnerman: "Ser pertinente es estar en contacto con las políticas, con el mundo del trabajo, con los demás niveles del sistema educativo, con la cultura y las culturas, con los estudiantes y profesores, con todos, siempre y en todas partes". (Tunnermann, 2000). Los niveles básicos e intermedios, aportan de forma significativa al crecimiento y formación del ser humano, son procesos claves 
para la auto construcción del ser por lo que la pertinencia debe ser considerada desde los niveles educativos formativos. Necesariamente, se debe tomar en cuenta las necesidades de la educación de los sujetos que proyectamos a la sociedad y al mercado laboral. Su formación critica, reflexiva y flexible tiene que ser replanteada desde los primeros años de formación básica; siendo así, es necesario explorar la pertenecía con los requerimientos sociales, con su rol dentro de la sociedad, (deberes y derechos de la niñez), como expositores y transmisores de cultura, tomando en cuenta las capacidades de la nueva generación milenios inmersa en un entorno cada vez más tecnológico, basados en esto, se puede decir que la pertinencia está determinada por el papel que cumple la educación en la sociedad y lo que espera la sociedad de ella, directamente incidida por las expectativas de los jóvenes.

Para cumplir dichos objetivos, la pertinencia exige de la educación y especialmente de la educación superior, tomar en cuenta problemas sociales del entorno, que sean estudiados, analizados e investigados. Para esto, debe existir una retroalimentación con los sectores pertinentes y de esta manera garantizar agentes de transformación. Como la Dra. Hebe Vessuri investigadora del IVIC de Venezuela menciona: La pertinencia es la coincidencia entre lo que las instituciones de educación hacen y lo que la sociedad espera de ellas, refiriéndose entre muchas cosas especialmente a la vinculación que debe tener la universidad con la comunidad. (Instituto Internacional de la Educación Superior en América Latina y el Caribe, 2000).

No solo la universidad debe estar enfocada a la producción y a la economía, también tiene que estar enfocada a la región, a sus sectores políticos, económicos, sociales y culturales. Es decir, muchos autores definen a la pertinencia como un "deber ser" ligado a las necesidades y carencias de la sociedad en las cuales están insertas y direccionadas al contexto mundial en constante evolución y cambio vertiginoso, a esto no se puede separar las necesidades particulares de cada individuo como lo especifica Tunnerman. Esto exige que la misión de las universidades cambie y evolucione, pues se deben replantear los objetivos y metas que involucran los quehaceres docentes, parámetros de investigación y gestión académica. Esto facilitará la transformación de la educación a través de diseños curriculares flexibles que se acoplen a las exigencias cambiantes de la sociedad y del mercado laboral fruto de la globalización donde el requisito único para lograr esta flexibilidad y diseño curricular debe ser la libertad académica.

Noraida Marcano percibe un nivel de pertinencia desde el interno de las instituciones y califica a la pertinencia interna como la capacidad de las instituciones para generar cambios en su entorno interno. Es decir, en su comunidad de profesores, estudiantes y muy particularmente en su currículo, el cual debe abarcar estrategias innovadoras que vincule la institución con su entorno para dar soluciones a problemas sociales. (Marcano, 2002). Explica también que el currículo como herramienta para la pertinencia debe incorporar problemas del contexto social en la cual la institución se inserte y se formen profesionales emprendedores. El currículo basado en el aprendizaje debe presentar alternativas que satisfagan tanto las expectativas de los estudiantes como las de su entorno social.

Se puede plantear cuatro ejes generales para explorar la pertinencia:

Pertinencia filosófica: Se enfoca en crear nuevos paradigmas, discutir tendencias e ideologías y democratizar el conocimiento; es decir, construir educación critica. 
Pertinencia científica: A través de la investigación se pretende minimizar las desigualdades, ser transformadores del contexto social y contribuir al desarrollo social.

La Pertinencia social: Tiene que ver con la búsqueda de la solución de problemas sociales, del Estado, los sectores públicos, el entorno cultural, de la democratización del conocimiento, de la interculturalidad y respeto al medio ambiente.

La pertinencia institucional: Se refiere a la noción transformadora de las instituciones educativas consigo mismas, de su capacidad de percibir las necesidades sociales e incluir los problemas inherentes a su entorno como parte de su currículo para ser analizados y proponer transformaciones en beneficio de su contexto, para esto debe proponer docentes investigadores, el conocimiento basado en aprendizaje y un currículo flexible que le permita incorporar el tratamiento de problemas sociales.

Si la pertinencia de la educación es imperante en tiempos de cambio y de crisis, esta debe ser explorada desde la construcción de la educación, desde su concepción, nacimiento, fundación, apogeo, crisis y proyección futura como un nuevo renacimiento de manera que podamos entender la trasformación de la sociedad en el tiempo. Ser críticos de ¿Cómo la educación ha sido total o parcialmente pertinente a la sociedad o la sociedad ha sido pertinente a la educación?, ¿La escuela y universidad medieval tenían conceptos de pertinencia?

\section{La educación en la era medieval}

A Platón se le adjudicaba la palabra academia cuando daba clases de matemáticas, filosofía, medicina, derecho y letras, en la Polis (estados griegos) se daba instrucción para la transmisión de los oficios; de igual manera Confucio, Buda o Lao Tse, instruían en los monasterios orientales. En la Roma antigua la educación tenía un nexo social, esta se estructuraba en una cadena de saberes que engranaban y se conectaban con el modelo y el perfil de la sociedad (escuelas liceo o academia), las ideas se discutían en un foro sobre temas del arte, la observación de la naturaleza, saberes aplicados, teóricos y espirituales, así como roles profesionales.

Posteriormente a la época de la escuela medieval, si así se le podía llamar, definitivamente se puede decir que no había pertinencia alguna en la educación. Bajo un régimen feudalista que nació a partir del fin del imperio romano donde prevaleció socialmente la desigualdad e inequidad de clases con brechas enormes entre la nobleza, el clero y los vasallos, donde el clero era el único sector que accedía a la instrucción superior, ésta era una época donde predominaba la ignorancia. La escuela no fue pensada para todos, como registros de la primera escuela se podría mencionar a la escuela palatina fundada por Carlo Magno en el palacio de Arquistán donde se educaba a los hijos del emperador y a los nutritti (alimentados) que eran los hijos de la aristocracia áulicos, aulici.

Carlo Magno instituyó la escuela medieval ordenando replicar a los obispos el modelo en catedrales y monasterios. Aquí toda formación surge alejada de los procesos productivos primarios de la sociedad en donde el intercambio económico entre Estados era escaso o nulo, la economía se basaba en la agricultura que era destinada a la subsistencia del feudal, o del campesino en forma individual. La instrucción escolar se basaba en el aprendizaje de la escritura primordialmente para uso político, -o racionalizar el uso de los recursos como lo hacían en oriente. 
La universidad medieval, también carente de pertinencia alguna, era una propuesta elitista, solo accedían los que disponían de recursos familiares, de hecho, hoy por hoy tampoco cumple con la universalidad por su naturaleza, se declara universal "en función de los méritos respectivos" . La característica universal de la universidad es el reclamo de su autonomía. Se crean las universidades medievales como una estrategia de organización más eficiente de los recursos humanos donde los profesores enseñan a estudiantes asiduos de aprender donde estos dan respaldo a la formación de las nacientes profesiones. Las universidades se convierten en instituciones gravitantes de influencia en la vida intelectual europea, se encargan de la generación de ideas de las cuales hacen uso para ejercer un poder intelectual al servicio de las elites eclesiásticas y civiles.

Tomando retazos de la historia de la escuela y universidad medieval se pueden entremezclar sus orígenes, nacen del mismo principio y base política, tanto universidad como escuela sin definición precisa, ni características propias, nace exclusivamente para un sector específico social que es el dominante y adquiere perpetuidad de dominio a través de la apropiación del conocimiento. Tanto el clero como las élites civiles hacen uso de la ignorancia del pueblo subordinado, solo los elit se reúnen y aportan ideas para marcar los rumbos de la sociedad y manejan la carente economía dirigida a sectores exclusivos. La diferencia del nacimiento entre universidad studium generale y escuela, está marcada por su concepción en dos diferentes campos. La universidad nace de la reunión de maestros que desean transmitir conocimiento y alumnos deseosos de recibirlo regidos por autoridades eclesiásticas o civiles, la universidad debía ser confirmada por autoridades universales como el Papa y el emperador, esta confirmación daba derechos a profesores y alumnos posiciones que marcaban un estatus social que gozaban de beneficios eclesiásticos y regalías, no pagaban impuestos y no participaban en el ejército, se colocaban bajo la salvaguardia de quien era autoridad fundadora.

Era también la autoridad universal quien validaba los títulos y adjudicaba las licencias para enseñar (licentiae docenci), esta licencia permitía al portador ejercer la docencia en cualquier institución de la cristiandad. Los títulos de Doctor o Maestro eran el máximo estatus educativo e intelectual y acreditaban a ejercer cualquier oficio y merecer los más altos honores. (Relancio, 2007).

Relancio menciona que algunas Studia generalia no recibieron su confirmación por parte del Papa en cuanto a su estatus oficial, uno de esos casos es la Universidad de Oxford. Las escuelas catedráticas studia o escuelas de las órdenes mendicantes implantaron currículos similares a las de las universidades, a diferencia de las universidades las escuelas respondían exclusivamente a las autoridades locales, en su gran mayoría religiosas y por su puesto los estudiantes no tenían los privilegios que los estudiantes universitarios ni sus títulos eran oficiales. Relancio también establece un análisis del interno de las universidades medievales que vale la pena mencionar y analizar cuya estructura no ha cambiado hasta el día de hoy en la mayoría de los casos. Las universitas nacieron como agrupaciones gremiales que fueron creando sus propios estatutos y su propia autonomía que no está al margen del control de autoridades religiosas o laicas.

En universidades como Oxford o la universidad de Paris solo los maestros tenían derecho a ejercer cargos y ser miembros de los consejos, mientras que los estudiantes servían a miembros 
de la universidad de grados intermedios y altos, como a escribas, estudiantes de élite, etc. También existían universidades donde los estudiantes eran los representantes de la comunidad universitaria, estos incluso sugerían maestros para ser contratados en forma anual para tal o cual cátedra, de hecho, esta forma de docencia existía de manera común donde los maestros conformaban gremios de doctores o colegios de doctores agrupados por disciplinas que tenían funciones de crear exámenes sobre las disciplinas específicas y de validar los títulos otorgados. De esta manera trabajaban las universidades de Bolonia y Padua, también la estructura podía ser mixta donde los estudiantes conformaban ciertos cargos universitarios dentro del consejo.

En forma general las universidades estaban caracterizadas por el lugar de fundación, pero estaban divididas internamente por las nacionalidades de las que provenían los estudiantes, ya que las universidades eran centros de encuentro de estudiantes de todas las proximidades. Desde ese entonces también las universidades se dividían en facultades por disciplinas de la misma manera que ha seguido ocurriendo hasta nuestros días, podían tener facultades de artes, filosofía, teología, derecho, medicina, entre la más comunes donde la estructura no ha cambiado, cada facultad tenía su propio consejo, estatutos y decano. La universalidad de las instituciones de educación superior era pregonada, su alcance llegaba más allá de un límite geográfico o político, se aceptaban estudiantes de distintos orígenes, pero en la gran mayoría de las universidades solo se aceptaban estudiantes que pertenecían a la cristiandad. Al ser los estudiantes de lugares aledaños próximos o lejanos a la localidad de origen de la universidad, la sociedad brindaba facilidades económicas para los estudiantes forasteros, por ejemplo, cobrar una tarifa diferenciada en los precios de alojamiento o comida.

La metodología de enseñanza señala Relancio, era basada en la escolástica, usaban la discusión y la disputa para tratar los temas dentro de clase como técnica didáctica para analizar los textos oficiales de cada disciplina y la segunda técnica era el debate oral donde se refería a los autores de los textos oficiales para tratar casos ejemplificadores y debates que podían surgir entre varios autores. Esta metodología exigía una relación maestro-discípulo muy estrecha, la memorización de textos era usada como herramienta de aprendizaje, las carreras podían durar desde cinco años hasta quince años en ciertos casos como la teología.

La escolástica también era empleada en la escuela medieval en los monasterios y catedrales como metodología de enseñanza. En lo que si se distingue la universidad era en la implementación de un examen final que por lo general se daba de forma oral para la aprobación y obtención de un título.

Finalmente, el contenido de las materias estudiadas en la edad media no estaba directamente dirigido hacia los fines necesarios de la sociedad ni mucho menos a minimizar los problemas sociales, por lo que en este sentido eran poco pertinentes con la sociedad que en la época primaba la desigualdad de clases sociales cuya brecha era muy grande. Los conocimientos ofrecidos en la universidad medieval tenían relación con las artes liberales de los romanos, enfocados en el derecho y la vida pública, incluía el estudio de la gramática, la lógica, y la retórica también primaba el estudio de la teología. En lo relacionado a las ciencias duras se estudiaba las matemáticas de la aritmética, la geometría, la astronomía y la música. Estas artes y ciencias eran aplicadas en la sociedad únicamente en el estrato élite social, los estudiosos en la 
medicina y las leyes por lo general brindaban sus servicios y se reservaban cargos cercanos a los monarcas, la nobleza y las clases altas de la sociedad.

Jorge Eduardo Noro explica que la escuela no comparte la misma matriz que la universidad, la escuela se desenvuelve en monasterios y órdenes religiosas a donde acuden niños y adolescentes para asegurar su incorporación en la sociedad y a la confesión religiosa. En cuanto a las cátedras la escuela se diferenciaba a la universidad ya que se impartían a diario con una serie de conocimientos en forma simultánea con un maestro único donde el estudiante no podía elegir sus cátedras, modalidad que se lleva hasta la actualidad, el estudiante debía ser un memorista y aprender al pie de la letra lo impartido y aprendido en los textos.

La certificación se obtiene al concluir el tiempo requerido, para esto los estudiantes se agrupaban por edades, es aquí cuando la escuela impone su distribución de espacios con el maestro al frente del salón en un lugar de control y los alumnos con sus bancas formando hileras en espacios rectangulares. Con el tiempo las escuelas se asocian entre sí, integrando un mismo currículo, método de enseñanza, reglamentos y modalidades, la escuela con el tiempo será una exigencia de cumplimiento obligatorio para salir a la sociedad e interactuar entre la sociedad, la escuela y la familia. (Noro J., 2016).

\section{La escuela moderna sus cimentos y estructura}

En la escuela moderna podemos vislumbrar la formalización e institucionalización de la educación donde adquiere un rol más predominante con la sociedad la escuela moderna es la etapa de florecimiento de la educación, si de una figura pertinente habláramos es aquí donde la aproximación a esta es mayor en el tiempo y de esta capacidad pertinente de la época echa mano el estado para hacer cumplir a la educación un rol fundamental en el desenvolvimiento social, como eje del progreso económico haciéndola parte de la industria, convirtiendo a la educación en el proveedor máximo del estado de ciudadanos trabajadores, útiles a la nación, conscientes de su afán de servir y producir para el estado en pos de un crecimiento familiar y social en busca del progreso. En la escuela moderna podemos vislumbrar la formalización e institucionalización de la educación donde adquiere un rol más predominante con la sociedad. La escuela moderna es la etapa de florecimiento de la educación, si de una figura pertinente habláramos es aquí donde la aproximación a esta es mayor en el tiempo y de esta capacidad pertinente de la época echa mano el Estado para hacer cumplir a la educación un rol fundamental en el desenvolvimiento social, como eje del progreso económico haciéndola parte de la industria, convirtiendo a la educación en el proveedor máximo del Estado de ciudadanos trabajadores, útiles a la nación, conscientes de su afán de servir y producir para el Estado en pos de un crecimiento familiar y social en busca del progreso.

Este momento es donde la educación adquiere un alto grado de pertinencia histórica ya que su rol se ajusta a los requerimientos personales del ciudadano, cumple los anhelos sociales y ejecuta la función que le da el estado al cumplir un rol social fundamental de manera filosófica al sostener los relatos dados inicialmente por la iglesia y asumir los nuevos relatos que el estado le encarga de implantar. Además, cumple también su rol social al formar para estos ciudadanos nacionalistas serviciales y productivos, finalmente es pertinente científica e institucional cuando sostiene un currículo que produce los que económicamente, socialmente y culturalmente el entorno requiere la educación adquiere una política normalizadora para los fines sociales. Se 
convierte como con gran exactitud y certeza la califica Jorge Eduardo Noro a la educación como una perfecta máquina de educar.

Jorge Eduardo Noro nos revela dos momentos de la educación moderna, el primero la sacralidad, que tiene como origen la matriz eclesiástica y usa como poderosos relatos para sostenerla a la fe, un segundo momento a la secularización donde se instalan nuevos relatos, otros fines, otros ideales, nuevos valores pero mantiene el modelo, los medios, los instrumentos y los rituales que le permiten darle una pertinencia especial a la educación para con el estado de quien la sociedad establece un rol paternalista el cual hace de la educación universal, obligatoria, gratuita, y sobre todo deseada socialmente.

Según Foucault la característica más preponderante del gobierno de la modernidad es no solo intervenir en la estructura del Estado o su dirección política, sino su interés se centraba en la dirección de la conducta social que involucra influir en los comportamientos sociales de la época, define lo que el ciudadano debe hacer en pos del progreso del estado utilizando estrategias para influir en la libre determinación de los ciudadanos. (Noro J. , 2016)

El gobierno es el pregonador del ejercicio de la libertad, una libertad que surge de los aprendizajes sociales y de las regulaciones, una libertad que se mueve estrechamente dentro de lo que el gobierno impone socialmente, son límites de libertad marcados socialmente. Es en este momento en que la escuela aparece ordenadora, haciendo uso para el estado lo que ella trae consigo su estructura, capacidad de formar individuos, ciudadanos los cuales se empoderan de los relatos fuertes de raíces profundas que la escuela acarrea, siembra traídas del ejercicio del poder pastoral y la gran influencia de la fe y de los cuales ella misma se sirve para colaborar con los fines del estado.

El poder pastoral en función de la imagen metafórica cristiana del pastor, hace ejercicio en la sociedad implantando saberes en lo subjetivo en la conducción espiritual del individuo, donde se crea discursos que regulan con poder sobre los actos sociales de forma reguladora que al final se convierten en actos sociales impositivos. La escuela a través de la matriz eclesiástica da el rol de pastor al docente como responsable del rebaño quien dirige y finalmente ejerce poder sobre el por lo que finalmente es usado al servicio del estado. Esa es la característica de estos dos momentos mencionados por Jorge Eduardo Noro, la fundación de la matriz eclesiástica como primer momento y el uso de su fuerte estructura con la implantación de nuevos relatos por el estado.

\section{Sacralización}

El primer momento conocido como sacralidad tiene como origen la matriz eclesiástica, monástica sostenida por poderosos relatos (acto de fe), sus fundadores implantan la universalidad de la educación y sobre todo su obligatoriedad que nace de la consciencia para con las prácticas religiosas. Es imperante socialmente educar en la fe, educación que tiene fines de evangelización con un propósito de reclutamiento donde se afianzan las convicciones y los discursos de la formación religiosa, esta convocatoria también asigna un rol formador a la familia que integra el conjunto educador en la fe. Para los fundadores Lutero, Calvino, el Concilio de Trento, Erasmo de Róterdam, la escuela tiene fines de formación y conquista religiosa, este proceso es puesto en práctica en las escuelas en bien definidas y estructuradas por Loyola Calasanz y La Salle. La 
obligatoriedad por parte de la familia de inculcar la formación religiosa es trasladada a la obligatoriedad de brindar a los hijos la educación que es regulada, autorizada, supervisada por la iglesia y las órdenes religiosas a cargo de impartir educación.

Se evidencia la influencia de matriz eclesiástica hasta nuestros días; la misma sacralidad del templo se evidencia en la sacralidad en el templo del saber. Muchas congragaciones desarrollaron extensos manuales para el manejo de la escuela, un ejemplo es la ratio studiorum para homogeneizar las prácticas educativas y la estructura física misma de la escuela. Se puede apreciar cómo se ordenó e incluso se diseñó físicamente pensada en la concepción de la iglesia. Se toma la estructura de separación y aislamiento del entorno de la concepción monástica, la distribución de los pupitres, respecto a los bancos de los fieles, la posición del escritorio del maestro al frente en la misma posición que el altar en la iglesia. La iglesia prepara al maestro y le ofrece un método confiable al clasificar a los alumnos, la manera de seleccionar los textos y fragmentar los contenidos, el silencio y obediencia de igual manera que el celebrante de la misa, el maestro ofrece aprendizaje y los alumnos aceptan el contenido de igual manera que el celebrante y los fieles.

Se encuentran similaridades en la didáctica a través de la presentación, explicación, memorización, evaluación; por ejemplo, el mecanismo del examen estaba instalado en el corazón de la práctica religiosa (examen de conciencia). Dentro de la clase se establecen rituales, se establece una calendarización y ciclos de los años escolares, de igual manera que la calendarización litúrgica. En resumen, disciplinamiento, orden, encierro y seguridad de igual manera que en las órdenes religiosas.

\section{Secularización}

En un segundo momento de la escuela moderna (Secularización) donde el estado consiente de la influencia profundad de la formación educativa en el comportamiento social y la psicología conductista, se apropia del modelo educativo de las órdenes religiosas. Esto ha conllevado a la implantando nuevos relatos legitimadores sociales, encaminar hacia la universalidad, la igualdad, la homogeneidad y la uniformidad, con el propósito de moldear a los sujetos, hacer de ellos lo que la iglesia, el estado y la sociedad requieren (sociedad tripartita). La sociedad reclamaba trabajadores dóciles para las minas y las fábricas, soldados útiles para el ejército, servidores civiles subordinados, empleados sumisos entrenados para cumplir doctrinas y normas de conducta. La educación brindaba ese tipo de ciudadano ideal y productivo. Los maestros daban directrices, entrenaban, y los alumnos obedecían, atendían, trabajaban, cumplían y repetían.

La escuela cumple la función de controlar el buen orden, enseña a marchar, establece horarios, homogeniza a los alumnos. Esta metodología homogénea y racional es garantía de sistema y procura los resultados educativos deseados, la educación produce individuos productivos que procuran el aprovechamiento del tiempo y los recursos convirtiéndose en instrumentos de trabajo disciplinados y obedientes con un compromiso cívico y patriótico que la sociedad exige, ciudadanos apegados a la moral, alejados de los vicios y de buenas costumbres, por lo que en la modernidad la educación era la exigencia de paso obligatoria para cumplir un rol social. La escuela con este propósito debía conservar su matriz eclesiástica original, pero debía secularizar sus objetivos, propósitos y sus fines. 
Para esto la modernidad hizo uso de la razón, así que, filosóficamente la secularización de la educación toma forma gracias al racionalismo metodológico, mismo que explica que todo conocimiento procede de la razón, fundamentos que el estado se encarga de validar. Posteriormente se toma en cuenta la teoría científica, gracias al positivismo se operan transformaciones sistematizando el saber y el conocimiento construyendo científicamente un modelo de sociedad cuyo fin máximo es el orden y el progreso. Así, el sistema educativo se convertía en la mayor herramienta para la homogenización y construcción de la nacionalidad y fortalecimiento del poder del Estado que es a su vez quien autoriza y supervisa el funcionamiento de las escuelas determinando sus contenidos y metodologías. Por lo tanto, la escuela se vuelve dócil a las demandas de la realidad social.

Noro cita a Pineau y menciona: escuela y modernidad se mimetizan, la modernidad le confiere a la escuela el puesto y la función que ninguna otra época le otorgó, naturaliza su presencia. Es decir, hubo escuela por la modernidad la demandó y hubo modernidad porque la escuela fue su fiel interprete. (Noro J. 2016). Y nos podemos preguntar iel sistema educativo se hizo pertinente a la modernidad o la modernidad desarrollo pertinencia con el sistema educativo?

Para ser pertinente la educación a la modernidad fue necesario que se fusione con las necesidades y el contexto, que sea la clara expresión de la relación entre los que su contexto expresa versus lo que la educación es en realidad. El contexto de esa época gravitaba la emancipación del conocimiento y de las ciencias, el conocimiento del mundo y del universo, el fortalecimiento del Estado fuerte y paternalista, la revolución, tecnología e industrial con un ciudadano entrenado para ser la fuerza productiva que necesitaba la industria y una sociedad que pregona la moral y los derechos humanos.

\section{¿Cómo llegamos a la escuela de hoy?}

La desacralización de la educación es la perdida de sentidos de los relatos fundadores y posteriores relatos de la modernidad que producen las crisis de la educación. Consecuentemente, se ha dejado de responder a las demandas de una sociedad mutada en un contexto de cambio vertiginoso por la posmodernidad con nuevas exigencias lejanas a aquellas plantadas por la modernidad. Esto ha hecho que la sociedad pierda confianza en los relatos que no pueden ser sostenidos en el tiempo. La matriz misma de la educación ha perdido cimientos para perder valor social; sin embargo, la educación conserva neciamente los rituales, contenidos y reglamentos, reproduciendo una y otra vez lo sagrado ante la falta de credo por la presencia de nuevos significados sociales y de una nueva visión que deslegitiman los relatos a razón del incumplimiento de promesas. Siendo así, se ha marcado escepticismo en la sociedad que no cree más en la función de la escuela, la legalidad de las normas, el valor del trabajo, la obligatoriedad y la homogeneidad.

Se produce una desvinculación entre la sociedad y la escuela debido a los cambios profundos en el contexto a consecuencia de que varios factores entran en crisis como la familia, la función disciplinadora de la educación, fin de los métodos tradicionales del aprendizaje, crisis de la obligatoriedad de la escuela, nacimiento de nuevas formas de educar, cambios en las fronteras y territorios, tecnologías de que derrumban antiguas concepciones y finalmente el divorcio del estado con la educación y la familia como lo describe Jorge Romero y Pedro 
Romero en la historia de infidelidad, celos y melancolía que ellos titulan La Marrana . (Jose Romero, Pedro Romero, 2014)

La escuela de nuestros días dice Jorge Eduardo Noro, es una escuela profanada con actitudes de menosprecio y rechazo, privada de hacer lo que se le demanda, agredida, objeto de violencia y desacreditación. La escuela ha sido convertida en un espacio público en el que se hace y se dice de todo, ha quedado huérfana de protección con la consecuente pérdida de autoridad y respeto, un escuela criticada, discutida e ignorada que se debate entre la modernidad y la necesidad de transformación que le exige un contexto desafiante y vertiginoso.

\section{Retos de la educación de hoy}

Dentro del nuevo contexto globalizante, presencia de nuevas formas y métodos de aprendizaje, además, es necesario tomar en cuenta la desenfrenada caída de las barreras del tiempo y espacio fruto de las tecnologías de la comunicación, es necesario replantearse una escuela adormitada ante cambios evolutivos sociales dinámicos. Evidentemente, hay nuevas maneras de relacionarse por lo que es necesario replantear el sistema educativo para que compagine con la sociedad actual, que tenga la flexibilidad de adaptación permanente antes nacientes necesidades y que se adapte a nuevas realidades sociales.

Se requiere una educación proactiva acorde a los problemas actuales con la capacidad de enfrentar nuevos retos del conocimiento en diversos aspectos: filosóficos, tecnológicos, sociales y culturales que busquen permanentemente las no caducas utopías de igualdad, universalidad libertad de pensamiento, inclusión y que para lograrlo tenga que fundar nuevos valores interpersonales con la naturaleza y el entorno promoviendo el entendimiento del nuevo ser humano de manera individual y colectiva. La necesidad de contar con una educación pertinente y de calidad es el reto actual de la educación básica y superior; esta última juega un papel importante, transformador, generador de investigación y desarrollador de nuevas técnicas y formas de conocimiento para mejorar los otros niveles educativos que tendrán que responder a retos y requerimientos sociales.

La sociedad actual rehuyente de expresiones de la educación moderna como la obligatoriedad, la imposición de contenidos, el enclaustramiento, la coartación de libertad de acción y pensamiento, la rigidez disciplinaria excesiva, métodos de enseñanza unidireccionales entro otras, exige profesionales educadores con capacidad transformadora. Es fundamental empezar a transitar este camino en un contexto diferente que incentive el crecimiento individual (aprender a aprender) y de aquellos que lo rodean, en un ámbito inclusivo que genere una escuela como un lugar de encuentro y que fomente el querer ejercer el derecho a la educación con espacios de libertad y ambientes flexibles. El reto sería construir una escuela no limitante en el tiempo, sin cronogramas establecidos o contenidos impuestos y sobre todo generadora de nuevos saberes tendientes a fomentar el buen vivir.

\section{Consideraciones para lograr la pertinencia.}

Para lograr la pertinencia de la educación en tiempos actuales, es necesario asumir un compromiso social que pueda lograr un cambio en las instituciones en particular, y en la sociedad en general. La pertinencia debe ser ejercida según Noraida Marcano desde la perspectiva filosófica, social, científica e institucional, para lo cual las instituciones deben 
contrastar en el deber ser, es decir, contrastar sus propuestas con la realidad de su entorno en un proceso de autoevaluación necesario. Sería importante examinar su función social, producción, distribución de conocimientos y tecnología. Deben asumir el reto de donde el estudiante sea mucho más activo en la apropiación del conocimiento, el docente asuma un papel de orientador en las posibilidades de acceso al mismo, manejo de información que demanda la nueva sociedad del conocimiento y finalmente la transferencia de conocimientos a la producción.

La modernización de la educación es un reto permanente para las instituciones educativas, tanto el conocimiento y cultura que se transfiere a la sociedad, tienen que fundamentarse en parámetros globales y regionales para el desenvolvimiento pleno de nuestras sociedades y garantizar el bienestar y desarrollo adecuado de las nuevas generaciones (Tunnermann, 2000).

Otra consideración importante es la integración de la investigación y la docencia; además, el tratamiento de los problemas nacionales y regionales para contribuir a la formación con sentido crítico que debe ser ejercido con rigor científico y responsabilidad intelectual e integral de los estudiantes. Para esto, la universidad actual debe establecer vínculos con los sectores sociales, empresariales y gubernamentales, siendo así, la libertad académica y la autonomía son esenciales para alcanzar objetivos de relevancia. Finalmente, la posición de la educación debe asumir un sentido ético que le permita afrontar los actuales devenires y rápidas trasformaciones tecnológicas que cambian a las sociedades y afectan la vida individual y colectiva que amenazan con franquear asideros morales.

\section{Bibliografía}

Aburrido, p. d. (2010). Ignacio Lewkowicz. Buenos Aires: Paidos.

Dussel, I. (2011). Aprender y enseñar en la cultura digital. VII Foro Latinoamericano de Educación, 3-94.

GIBBOn, M. (s.f.).

Gibbons, M. (1998). Pertinencia de la educación superior en el siglo XXI. Banco mundial, (pág. 81). Washington.

Hargreaves, A. (2005). Profesorado, cultura y posmodernidad. London: Morata.

House, E. R. (1988). Tres perspectivas de la innovacion educativa, tecnológica, politica y cultural. Colorado: Revista de educación.

Igarza, R. (2010). Aula en tansición. 1-19.

Instituto Internacional de la Educación Superior en América Latina y el Caribe, V. 1.-2. (2000). Educacion superior y sociedad. Texas.

Jose Romero, Pedro Romero. (2014). La marrana. Rosario: Homo Sapiens.

Lewkowicz, I. (2010). Pedagogia del aburrido. Buenos Aires: Paidos.

Marcano, N. (2002). Pertinencia, compromiso social y curriculo en las Instituciones de Educación Superior . Encuentro educacional, 9.

Noro, J. (2016). Universida, escuela y sistemas educativos, historia y perspectivas. Rosario.

Noro, J. E. (2015). De la escuela del pasado a la escuela del futuro. Rosario.

Relancio, A. (2007). Las universidades medievales. Canarias.

Tunnerman, C. (2000). Pertiencia social y principios básicos para orientar el diseño de políticas de educación superior. Educación Superior y Sociedad, 181-196.

UNESCO. (1998). La educación superior en el siglo XXI, Vision y acción. Conferencia Mundial sobre la Educación Superior, (pág. 141). París. 